\title{
Study of Factors Affecting the Ablation Rate of Phenolic Resin/Fiber Glass
}

\author{
Nattawat Winya, Adulyasak Boonpan, and Komson Prapunkarn
}

\begin{abstract}
In this study, design experimental by two-level Factorial design to screen the factors to those factors that affect the ablation rate significantly. The following parameters were varied: amount of phenolic curing temperature and curing time. Factors that affect the ablation rate are as follows curing time, amount of phenolic resin, interaction between curing temperature and curing time, interaction between curing time and amount of phenolic resin, interaction between curing temperature and amount of phenolic resin and 3-way interaction of amount of phenolic resin, curing temperature and curing time. As the results of main effects analysis to determine 75 wt.\% of phenolic resin, curing temperature $160{ }^{\circ} \mathrm{C}$ and curing time $35 \mathrm{~min}$ to give the ablation rate was $0.121 \mathrm{~mm} / \mathrm{s}$ less than $0.14 \mathrm{~mm} / \mathrm{s}$ according MIL-l-24768 standard.
\end{abstract}

Index Terms-Phenolic resin, ablation rate, rocket motor, insulation.

\section{INTRODUCTION}

Composite materials are widely used in various industries such as automotive, construction, furniture air and interior materials. The properties of composite materials with high strength, tough, lightweight, long life and can be easily molded [1]-[4]. The material is made from composites can be used instead of the natural materials. Such as steel, which are not in the corrosion and rusting. While the wood over time. Strength would be reduced. The composite consists of a matrix material serves to hold the reinforcement together and the fibers act as reinforcement. It is the strength of the material. The matrix used in this research is a phenolic resin has properties that can withstand high heat and very strong. When combined with a fiber reinforced. It makes composite materials with enhanced properties can be used in a variety of the industry. In the last few years, research has been focused on the development of new ablative materials made of polymer matrix reinforced with fibers. The ablative materials are used extensively in thermal protection such as hypersonic atmospheric or propulsion system of the rocket [5], [6]. The criteria for the selection of ablative materials in aerospace must be considered in terms of properties and characteristics of the material itself. The benefit of ablative is able to absorb high heat, good heat distribution, good insulation, light-weight, easy to find, good flexibility, inexpensive and design is easy [7].

Manuscript received March 25, 2013; revised June 28, 2013.

The authors are with the Chemical Engineering and Metallurgy Laboratory, Research and Development Department, Defence Technology Institute (Public Organization) Ministry of Defence, The Kingdom of Thailand, 47/433 ,4th Floor-Office of the Permanent Secretary of Defence Building, Changwattana Rd., Pakkred, Nonthaburi, Thailand (e-mail: nattawat.w@dti.or.th).
Phenolic resin is the first synthetic plastic prepared from phenol and formaldehyde. This is a condensation reaction. Phenolic resin is cheaper, high thermal stability, excellent tension strength and compressive strength, good resistance to chemicals and solvents as well. Has a low water absorption rate, which is expensive components used in a plane or car [8]. The phenolic resin formed by compressing the fiber layer and the oven. This process is called forming a laminate [9]. The fibers used to form many types of glass fiber, carbon fiber and aramid fiber. The composite has been investigated in recent years for a type of phenolic resin and fibers. The fiber reinforcement is additive to the polymer as increase the strength and stiffness in the polymer. The glass fiber reinforced material used for the plastic that both thermoplastic and thermosetting. The properties of reinforced plastic with high strength, light weight properties, excellent dielectric properties, high dimensional stability and corrosion resistance [10], [11]. Including the ability to make a variety of molded plastic reinforced with glass fiber to be used in place of metal together and can be forming practical. It can be used with fiber-reinforced plastic instead of metal widely [12].

The purpose of this study was to investigate the effects of curing temperature and curing time of the composite to determine the best condition for ablative materials according MIL-1-24768 standard (ablation rate less than $0.14 \mathrm{~mm} / \mathrm{s}$ ).

\section{MATERIALS \& METHODS}

\section{A. Materials}

The commercial available resole phenolic resin was Thai GCI Resitop Co, Ltd., Thailand. With commercial code PL-9236 (see Table I). The commercial fiber was E-Glass CSM 450-1000 MM from FRP services and Co. (Shanghai), LTD

TABLE I: THE PROPERTY OF PHENOLIC RESIN

\begin{tabular}{ccc}
\hline \hline $\begin{array}{c}\text { Resole Phenolic } \\
\text { resin }\end{array}$ & Density@ $25^{\circ} \mathrm{C}(\mathrm{CP})$ & Gel time $\left(T=140^{\circ} \mathrm{C}\right)$ \\
\hline PL-9236 & $800-1200$ & $4-7$ \\
\hline \hline
\end{tabular}

B. Measurements

Ablation rate was measured using oxygen and acetylene ablation testing equipment according to ASTM E285 and calculate the ablation rate to the following by thickness/Burn-through time

Fourier-transform infrared spectroscopy (FTIR) was performed with a Spectrum One FT-IR spectrometer at a resolution of $4 \mathrm{~cm}^{-1}$

Nuclear magnetic resonance analysis with ${ }^{1} \mathrm{H}-\mathrm{NMR}$ technique with NMR Spectrometer. AV-500 Model of 


\section{Bruker Biospin Switzerland.}

\section{Characterization of Phenolic Resin}

The results of the characterization of phenolic resin by using FT-IR showed a double bond $\left(1595.66 \mathrm{~cm}^{-1}, 1699.47\right.$ $\left.\mathrm{cm}^{-1}\right)$, among the hydroxyl in $\left(3350.62 \mathrm{~cm}^{-1}\right)$ alkyl $(2978.70$, $2938.83,1456.38$ and $\left.1368.03 \mathrm{~cm}^{-1}\right)$ from H-NMR analysis showed that the type of aromatic compounds $(\delta=6.8-7.2$ $\mathrm{ppm})$, alkanes $(\delta=4.5 \mathrm{ppm})$ and an aldehyde $(\delta=9.2 \mathrm{ppm})$.
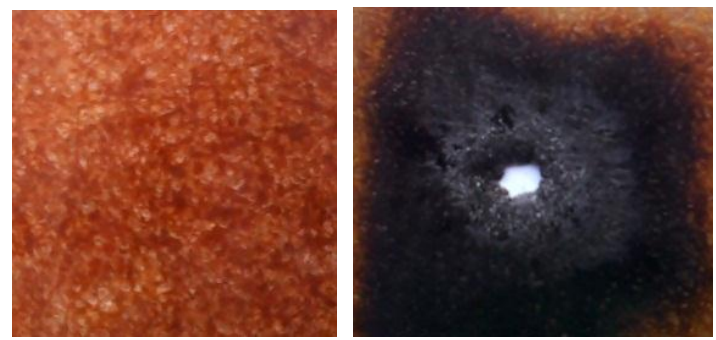

Fig. 1. Specimen before and after tested of phenolic resin/fiber glass

\section{Preparation of Fiber Glass/Phenolic Composite}

Preparation of phenolic composite by Cutting Glass fiber specimen size $50 \times 50 \mathrm{~cm}$ and hand lay up process in Fig. 1 The phenolic composite was forming laminate and put into the oven at $80^{\circ} \mathrm{C}$ for $4 \mathrm{~h}$ and then heated to $100{ }^{\circ} \mathrm{C}$ for $30 \mathrm{~min}$ and heated again to $120^{\circ} \mathrm{C}$ for 40 min in Fig. 2 and vary curing temperature see Table II. After that bringing to design experimental by 2-level Factorial design to screen the factors to those factors that affect the ablation rate. The following lowing parameters were varied: amount of phenolic resin, curing temperature and curing time.

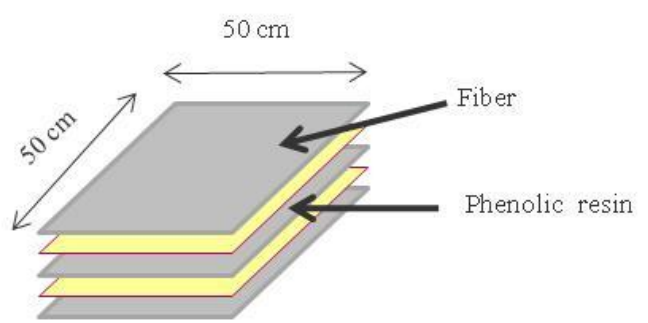

Fig. 2. Geometrical details of target configuration for composite laminates.

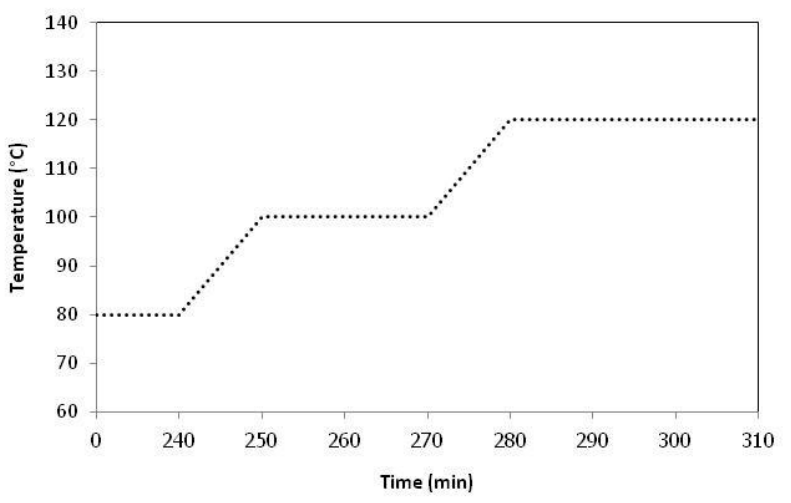

Fig. 3. Typical process procedures for phenolic resin/ fiber glass composite

\section{RESULTS AND DISCUSSION}

The following parameters were varied: amount of phenolic resin, curing temperature and curing time (see Table II.). The results of design experimental by 2-level Factorial design are used to analyze the results the ablation rate of phenolic resin/fiber glass with three replication of the experiment. It analyzes the factors that affect the ablation rate by creating a chart that is normal (Normal probability plot), as shown in Fig. 3, the factors that affect the response variable at significance level $\alpha=0.05$ are curing time (B) amount of phenolic resin $(\mathrm{C})$, interaction between curing temperature and curing time $(\mathrm{AB})$, interaction between curing temperature and amount of phenolic resin $(\mathrm{AC})$, interaction between curing time and amount of phenolic resin (BC) and three interaction of amount of phenolic resin, curing temperature and curing time $(\mathrm{ABC})$ affect the ablation rate.

TABLE II: SHOWS THE EXPERIMENTAL RESULTS FOR A 2-LEVEL FACTORIAL DESIGN

\begin{tabular}{cccc}
\hline \hline Sample & $\begin{array}{c}\text { Phenolic amount } \\
(w t \%)\end{array}$ & Curing Temperature $\left({ }^{\circ} \mathrm{C}\right)$ & Curing Time (min) \\
\hline 1 & 50 & 140 & 15 \\
2 & 50 & 140 & 35 \\
3 & 50 & 160 & 15 \\
4 & 50 & 160 & 35 \\
5 & 75 & 140 & 15 \\
6 & 75 & 140 & 35 \\
7 & 75 & 160 & 15 \\
8 & 75 & 160 & 35 \\
\hline \hline
\end{tabular}

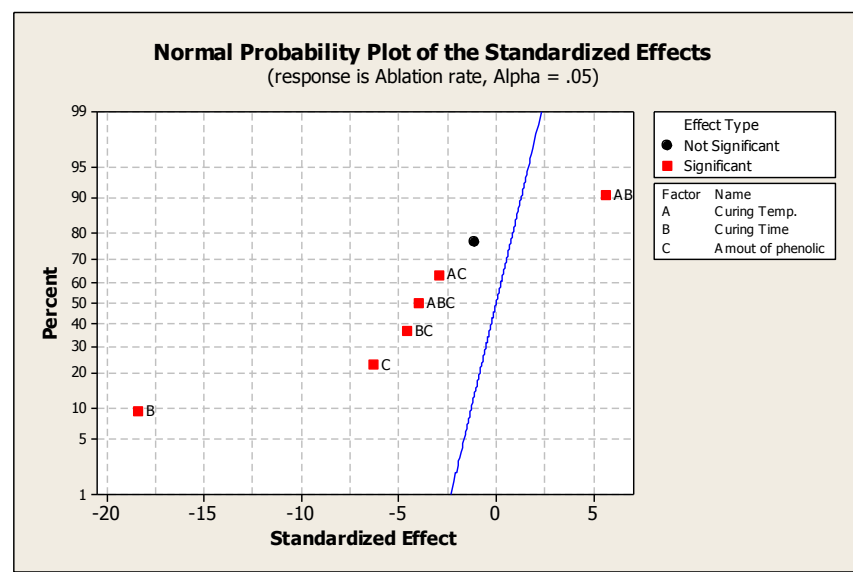

Fig. 4. This curve is normal probability plot of the standardized effects.

However, when considering the results of Pareto chart of effects observed in Fig. 4 by the red lines refer to the significance level $\alpha=0.05$, there are six factors that are affecting the response variable. While the one main factors that will affect the response variable, as well as close to the reference line and not to lose the opportunity to decide. Thus, adding to the factors in the model was then reduce model and analyze the results.

See in Fig. 5 residual plot the graph to determine the validity of the experimental model (Model Adequacy Checking) to see whether the data has a normal distribution. Which is independent and has a satisfactory stability. Thus data to be used in further analysis.

See in Fig. 6 reduce model analysis of variance (ANOVA) of the factors that will be affect the ablation rate is five factors as follows.

- curing time

- amount of phenolic resin 
- interaction between curing temperature and curing time

- interaction between curing temperature and amount of phenolic resin

- interaction between curing time and amount of phenolic resin

3-way interaction of amount of phenolic resin, curing temperature and curing time.

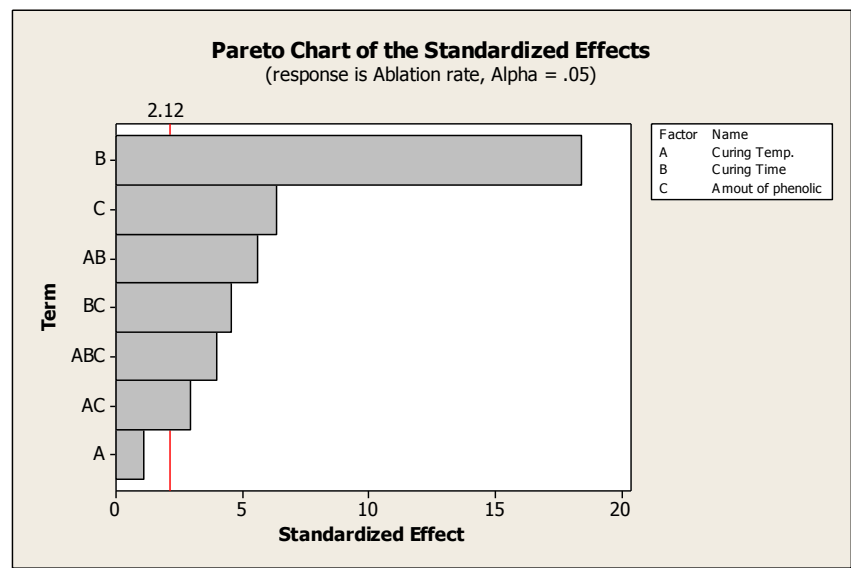

Fig. 5. Parato chart of the standardized effects.

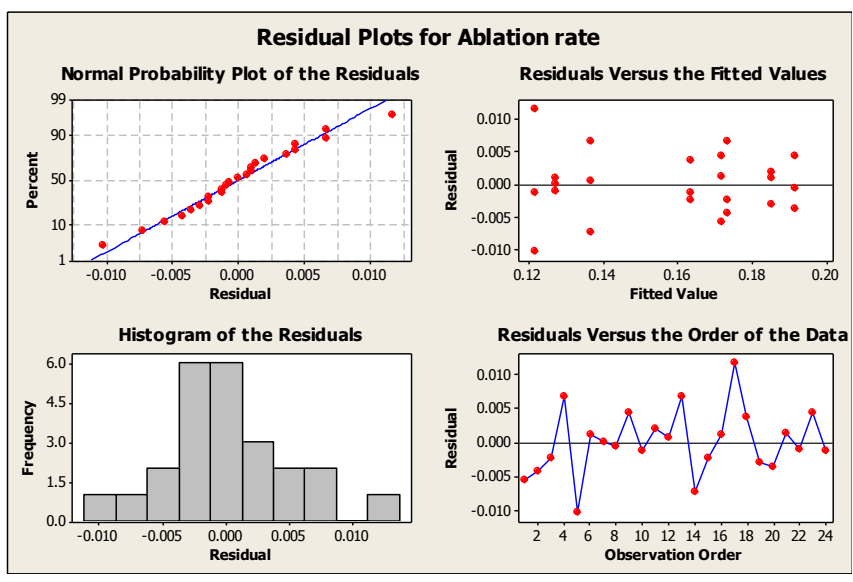

Fig. 6. Residual plots for ablation rate

\begin{tabular}{|lcccccc|}
\hline \multicolumn{7}{|c|}{ Analysis of Variance for Response (coded units) } \\
\multicolumn{1}{|c|}{ Source } & DF & Seq SS & Adj SS & Adj MS & F & P \\
Main Effects & 3 & 0.0126851 & 0.0126851 & 0.00422838 & 126.69 & 0.000 \\
2-Way & 3 & 0.0020338 & 0.0020338 & 0.00067793 & 20.31 & 0.000 \\
Interactions & & & & & & \\
3-Way & 1 & 0.0005320 & 0.0005320 & 0.00053204 & 15.94 & 0.001 \\
Interactions & & & & & & \\
Residual Error & 16 & 0.0005340 & 0.0005340 & 0.00003337 & & \\
Pure Error & 16 & 0.0005340 & 0.0005340 & 0.00003337 & & \\
Total & 23 & 0.0157850 & & & & \\
\hline
\end{tabular}

Fig. 7. Analysis of variance (ANOVA) for response

The effect of curing temperature, curing time and amount of phenolic resin affect the ablation rate of phenolic resin / fiber glass in Fig. 7 showed the results of main effects analysis that have the slope of the graph for curing time condition higher than curing temperature and the amount of phenolic resin. The demonstrated the curing time is affecting the ablation rate with more than two factor. Therefore when increasing the curing temperature, curing time and amount of phenolic resin. These factors will result in the ablation rate decreased as the result of the ablation properties increase. However, when analyzing the results of interaction effects plot in Fig. 8 have the interaction between the two factors that are the interaction between curing temperature and curing time, interaction between curing temperature and amount of phenolic resin and interaction between curing time and amount of phenolic resin which directly affects the ablation rate. Therefore, the main effects analysis to determine 75 wt. $\%$ of phenolic resin, curing temperature $160{ }^{\circ} \mathrm{C}$ and curing time 35 min that were the best condition.

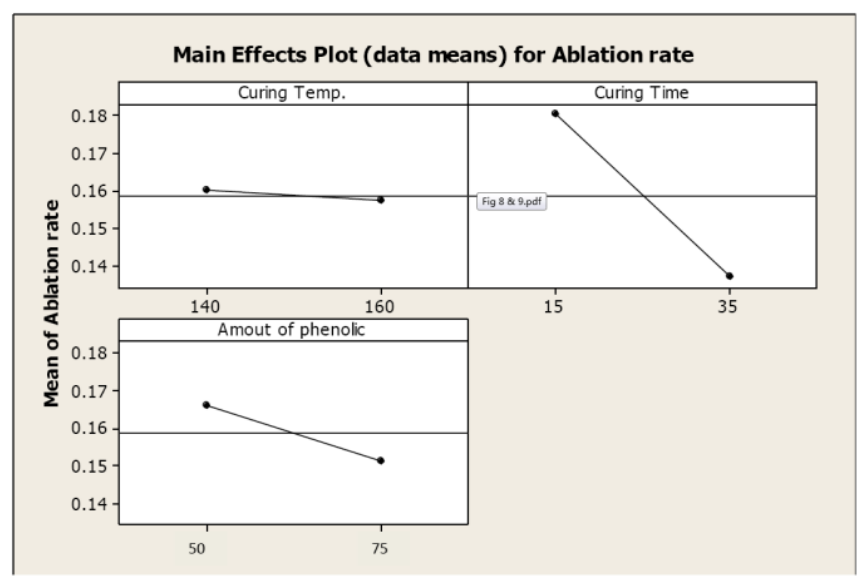

Fig. 8. Main effect plot for ablation rate.

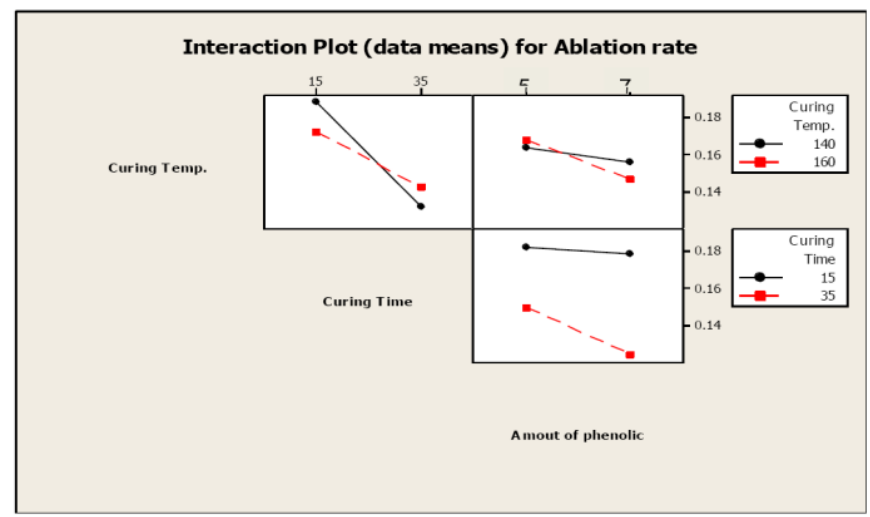

Fig. 9. Interaction plot for ablation rate.

\section{CONCLUSION}

From design experimental by two-level Factorial design. Five Factors that have affect to the ablation rate are as follows curing time, amount of phenolic resin, interaction between curing temperature and curing time, interaction between curing temperature and amount of phenolic resin, interaction between curing time and amount of phenolic resin, interaction between curing temperature and amount of phenolic resin and 3-way interaction of amount of phenolic resin, curing temperature and curing time. Results of main effects analysis to determine 75 wt.\% of phenolic resin, curing temperature $160^{\circ} \mathrm{C}$ and curing time $35 \mathrm{~min}$ to give the ablation rate was $0.121 \mathrm{~mm} / \mathrm{s}$ less than $0.14 \mathrm{~mm} / \mathrm{s}$ according MIL-1-24768 So, which were the best condition

\section{ACKNOWLEDGMENT}

This work was supported in part by Chemical Engineering and Metallurgy Laboratory, Research and Development Department, The Defense Technology Institute (Public Organization), Nonthaburi, Thailand. 


\section{REFERENCE}

[1] M. R. Firouzmanesh and A. ArefAzar, "Study of thermal stability and ablation behavior of carbon/epoxy-novolac composites," Journal of Applied Polymer Science, vol. 88, June 2003, pp. 2455-2461, 2003.

[2] D. W. K. Ho, J. H. Koo, and O. A. Ezekoye, "Kinetics and thermophysical properties of polymer nanocomposite for solid rocket motor insulation," J. Spacecraft Rockets, vol. 46, 2009.

[3] G. P. Sutton and O. Biblarz, Rocket Propulsion Element, 7th edition, John willey \& sons, New York, 2001.

[4] Design and manufacturing guideline for aerospace composites, Marshall space flight center, Guideline NO.GD-ED-2205, pp. 8, 2005.

[5] D. Wei, D. F. Li, L. Zhang, Z. K. Zhao, and Y. H. Ao, "Study on phenolic resin foam modified by montmorillonite and carbon fiber," Procedia Engineering, vol. 27, pp. 374-383, 2012.

[6] Y. Jiang, X. Zhang, J. He, L. Yu, and R. Yang, "Effect of polyphenenylsisesquioxane on the ablative and flame-retardation properties of ethylene propylene diene monomer (EPDM) composite," Polymer Degradation and Stability, vol. 96, pp. 949-954, January 2011.

[7] J. Lu, "Synthesis of Phenolic Resin Amines and Solid-State NMR of Phenolic Resin in NASA Rocket Motors," Mississippi State University, 1998.

[8] G. Pulci, J. Tirillo, F. Fossati, C. Bartuli, and T. Valente, "Carbon-phenolic ablative materials for re-entry space vehicles: Manufacturing and properties, Composite: part A," vol. 41, pp. 1483-1490, 2010.

[9] Military Specification: Insulation, Plastics, Laminated, Thermosetting, Generak Specification, February 1992.

[10] NASA space vehicle design criteria (Chemical propulsion) Solid rocket motor nozzles, National aeronautics and space administration, United state, 1975.

[11] M. Natali, J. Kenny, and L. Torre, "Phenolic matrix nanocomposites based on commercial grade resols: Synthesis and characterization," Composite Science and Technology, vol. 70, pp. 571-577, January 2010.

[12] Application of Ablative Composites to Nozzles for Reusable Solid Rocket Motors, Marshall space flight center, Practice no.PD-ED-1218, United state, 2005.

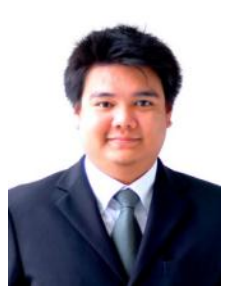

W. Nattawat was born on Nov. 1, 1983 in Bangkok, Thailand. He received the B.Eng. degree in Chemical Engineering from Kasetsart University and M.Eng. degree in Chemical Engineering from Kasetsart University. Currently, He is an researcher in Chemical Engineering and Metallurgy Laboratory, Research and Development Department, Defence Technology Institute (Public Organization) Ministry of Defence, The Kingdom of Thailand. His research interests include solid propellant and ablative materials.

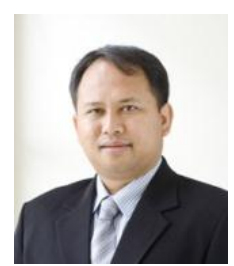

B. Adulyasak was born on Nov. 17, 1976 in Surin Thailand. He received the B.Eng. dregree in Mechanical Engineering from Khon Kaen University and M.Eng. Degree in Mechanical Engineering from Khon Kaen University. Currently, He is an researcher in Chemical Engineering and Metallurgy Laboratory, Research and Development Department, Defence Technology Institute (Public Organization) Ministry of Defence, The Kingdom of Thailand. His research interests include solid propellant and rocket motor case materials.

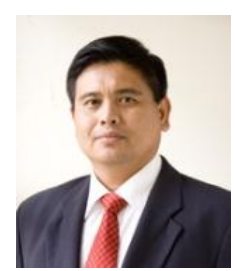

P. Komson was born on May 9, 1965 in Prachupkirikarn, Thailand. He received the B.Sc dregree in Chemistry \& Physical and Materials Sciences from Royal Thai Force Academy and M.Sc. degree in in Solid Mechanic and Materials Sciences at The George Washiton University USA.. Currently, He is an researcher in Chemical Engineering and Metallurgy Laboratory, Research and Development Department, Defence Technology Institute (Public Organization) Ministry of Defence, The Kingdom of Thailand. His research interests include genretic materials, solid propellant. 